\title{
Bioavailability of a New Generic Formulation of Imatinib Mesylate 400mg Tablets Versus Glivec in Healthy Male Adult Volunteers
}

Dalia Jawhari, Mahmoud AISwisi and Mahmoud Ghannam*

BSc Pharmacy, Jordan

\begin{abstract}
Imatinib is a highly selective inhibitor of tyrosine kinase used in the treatment of CML and GIST. However the cost of the drug is prohibitive especially in the developing countries. The aim of this study is to compare pharmacokinetics profile of a new Imatinib generic formulation (Imatinib tablets 400mg batch number: 2090602, Hikma Pharmaceuticals PLC) with those of Glivec, (batch number: S0143, Novartis Pharma AG, Basle, Switzerland) in healthy male volunteers /fed state. The study was single center, randomized, single dose, laboratory-blinded, 2-period, 2-sequence, crossover design. The study was performed by CRO Algorithme Pharma Inc, (Quebec, Canada) in accordance with Good Clinical Practices and the applicable regulatory requirements. Male volunteers, non- or ex-smokers, of at least 18 years of age but not older than 55 years with a body mass index (BMI) greater than or equal to 18.5 and below $30 \mathrm{~kg} / \mathrm{m} 2$ were selected according to the inclusion and exclusion criteria. In each study period, a single $400 \mathrm{mg}$ dose of Imatinib was orally administered with about $240 \mathrm{~mL}$ of water in the morning after a 10-hour overnight fast, thirty (30) minutes after the start of a high-fat, high-calorie breakfast. Subjects remained seated for at least the first 4 hours following each drug administration. In each study period, twenty (20) blood samples were collected by venipuncture in pre-cooled Vacutainers containing EDTA. The first blood sample $(2 x$ $4 \mathrm{~mL}$ ) was collected prior to drug administration while the others ( $1 \times 4 \mathrm{~mL}$ each) were collected at 1, 1.5, 2, 2.33, $2.67,3,3.33,3.67,4,4.5,5,6,8,10,14,18,24,48$ and 72 hours post drug administration. The drug administrations were separated by at least 14 calendar days. Urine drug and ethyl alcohol screening was performed before each period of the study. Hematology and biochemistry tests were repeated after the collection of the last blood sample of the study. Safety was evaluated through the assessment of adverse events, and laboratory tests. Imatinib plasma samples were analyzed employing a validated HPLC method using MS/MS detection. For a $400 \mathrm{mg}$ dose of Imatinib, the analytical range was approximately $10 \mathrm{ng} / \mathrm{mL}$ to $4000 \mathrm{ng} / \mathrm{mL}$. Descriptive statistics were used to summarize adverse events, safety results and demographic variables (age, height, weight and BMI). The main pharmacokinetic parameters of interest for this study were $C_{\max }, A \cup C_{0-T}$ and $A U C_{0-\infty}$. Other parameters such as $T_{\text {max }}, A U C_{T / \infty}, K_{e l}$ and $T_{1 / 2 \mathrm{el}}$ were provided for information purposes only. The natural logarithmic transformation of $C_{\max }^{\max }, A U C_{0-T}$ and $A C_{0-\infty}$ was used for all statistical inference. The mean (C.V. \%) of $C_{\max }, T_{\text {max }}, A U C_{0 . T}$ and $A U C_{0-\infty}$ for Imatinib were $1760.5 \mathrm{ng} / \mathrm{ml}(26.6 \%), 3.67 \mathrm{hrs}(26.4 \%), 30946.5 \mathrm{ng} . \mathrm{h} / \mathrm{ml}(28.0 \%)$ and $31912.5 \mathrm{ng} . \mathrm{h} / \mathrm{ml}(28.2 \%)$ versus $1779.4 \mathrm{ng} /$ $\mathrm{ml}(25.8 \%), 3.67 \mathrm{hrs}(39.0 \%), 31073.6 \mathrm{ng} . \mathrm{h} / \mathrm{ml}(25.7 \%)$ and $32270.9 \mathrm{ng} . \mathrm{h} / \mathrm{ml}(26.4 \%)$ for Glivec. The $90 \%$ confidence intervals of $C_{\text {max }}, A \cup C_{0-\mathrm{T}}$ and $A \cup C_{0-\infty}$ for Imatinib $400 \mathrm{mg}$ were $(92.00 \%-105.52 \%),(95.69 \%-102.31 \%)$ and $(95.23 \%$ $101.55 \%$ ) respectively. The ratio of the geometric LS means for the test to reference $C_{\max }, A \cup C_{0-T}$ and $A U C_{0-\infty}$ for Imatinib $400 \mathrm{mg}$ were $98 \%, 99 \%$ and $99 \%$ respectively with low ISCV $12.9 \%$ for $\mathrm{C}_{\max }$ and $6.3 \%$ for $A U \mathrm{C}_{0-\mathrm{T}}$ and $6.0 \%$ for $A \cup C_{0-\infty}$, The results indicated that the products are equivalent and switchable according to FDA rulings.
\end{abstract}

Keywords: Imatinib, Bioequivalence, Glivec, Tyrosine kinase inhibitor

\section{Introduction}

Imatinib is the 4-[(4-methyl-1-piperazinyl) methyl]-N-[4-methyl3-[[4-(3-pyridinyl)-2-pyrimidinyl] amino] phenyl] benzamide, which is represented by the following structure (Figure 1).

Protein tyrosine kinases participate in signal transduction pathways which regulate diverse cellular processes such as growth, metabolism,<smiles>Cc1ccc(NC(=O)c2ccc(CN3CCN(C)CC3)cc2)cc1Nc1nccc(-c2cccnc2)n1</smiles>

Figure 1: differentiation, adhesion and apoptosis [1,2]. Deregulation of protein tyrosine kinase activity has been associated with the pathogenesis of various cancers, including chronic myeloid leukemia (CML) and gastrointestinal stromal tumour (GIST), as well as other proliferative diseases [3].

CML is a hematologic stem-cell disorder associated with a specific chromosomal translocation known as the Philadelphia Chromosome (Ph). $\mathrm{Ph}$ is detected in $95 \%$ of patients with CML from which $20 \%$ of them have acute lymphocytic leukemia [4]. The molecular consequences of the $\mathrm{Ph}$ translocation is the fusion of the Abl (Abelson leukemia virus) proto-oncogen on chromosome 9 to the Bcr (breakpoint cluster

*Corresponding author: Mahmoud Ghannam, Jordan, E-mail: mghannam@apm com.jo

Received May 17, 2011; Accepted July 29, 2011; Published August 01, 2011

Citation: Jawhari D, AISwisi M, Ghannam M (2011) Bioavailability of a New Generic Formulation of Imatinib Mesylate 400mg Tablets Versus Glivec in Healthy Male Adult Volunteers. J Bioequiv Availab 3: 161-164. doi:10.4172/jbb.1000077

Copyright: @ 2011 Jawhari D, et al. This is an open-access article distributed under the terms of the Creative Commons Attribution License, which permits unrestricted use, distribution, and reproduction in any medium, provided the original author and source are credited. 
region) gene on chromosome 22. This results in the production of an activated Bcr-Abl protein tyrosine kinase [5].

Imatinib mesylate is the first and only effective drug for the treatment of gastrointestinal stromal tumour (GIST) at present. The constitutive activation of KIT receptor tyrosine kinase is critical in the pathogenesis of GISTs. This constitutively activated mutant isoform of KIT and/or kinase platelet derived growth factor receptor alpha (PDGFRA) are potential therapeutic targets for imatinib [6].

Imatinib mesylate is a highly selective inhibitor of Bcr-Abl, platelet-derived growth factor receptors, and c-KIT receptor tyrosine kinases [7]. Imatinib exerts its therapeutic effect in CML through competitive inhibition at the adenosine triphosphate binding site of Bcr-Abl signal transduction [8]. At the clinical level, this translates into selective inhibition of proliferation and induction of apoptosis in BcrAbl positive cells, with no effect on normal cells [3].

Imatinib is currently considered as the first line treatment for patients with newly diagnosed chronic phase CML. It is also indicated for all phases of CML after failure of interferon- $\alpha$ therapy, and for the treatment of malignant unresectable or metastatic (GIST) at doses of 400-600 mg/day [3].

Imatinib is rapidly absorbed after oral administration with a peak plasma concentration occurring at 2-4 hours [8]. The bioavailability of Imatinib is around $98 \%$ which is irrespective of dosage form(solution, capsule, or tablet) or dosage ( 100 or $400 \mathrm{mg}$ ) [3,10,11]. Additionally, iImatinib absorption is not significantly affected by food [12]. When given with a high fat meal, the rate of absorption of Imatinib was minimally reduced (only $11 \%$ decrease in Cmax and 1.5 hours increase intmax), with a small reduction in AUC (7.4\%) compared to fasting conditions [3]. Imatinib is extensively distributed into tissues and is highly protein bound, predominantly to albumin and a 1-glycoprotein (AGP), which is translated into a large volume of distribution ( $435 \mathrm{~L}$ ) and a long half life (18 h) [11]. The increase in mean Imatinib AUC with increasing the dose was linear and dose proportional in the range 25-1000 mg after oral administration [3].

There was no change in the kinetics of Imatinib on repeated dosing. The drug accumulation in blood is $1.5-3$ fold at steady state with multiple dose administration on a once daily schedule, compared with concentrations observed after the first Imatinib dose [3]. There is no effect of gender on the pharmacokinetics of Imatinib [3].

Imatinib is primarily metabolized through cytochrome P450 (CYP3A4) and CYP3A5 [11]. The main metabolite is the N-demethylated piperazine derivative, CGP 74588, which represents approximately $10 \%$ of the Imatinib AUC and has a similar potency in vitro [9].

Imatinib is mainly eliminated through the liver. The kidneys only excrete a minimal amount of the drug and its metabolites [12].

The aim of this study was to compare the bioavailability of two formulations of Imatinib mesylate $400 \mathrm{mg}$ tablets. A generic formulation developed at Hikma Pharmaceuticals PLC and a reference one (Glivec- Novartis), after a single oral administration of $400 \mathrm{mg}$ tablet to healthy volunteers.

\section{Materials and Methods}

\section{Ethics}

This study was only commenced after a written approval obtained by Canadian health authorities. The trial was conducted as per guidelines as drawn up by the Institutional Review Board (IRB) and followed with regard to the treatment of human subjects in this study. These guidelines meet the requirements of the Declaration of Helsinki. They also meet the requirements of the U.S Code of Federal Regulations (Title21, part56), the Directive 2001/20/EC (Europe) and the Tri-Council Policy Statement (Canada). Volunteers were informed about the study procedure and signed the informed consent form. The code that was assigned to the protocol of the study by the IRB was 1736 .

Hikma Pharmaceuticals ensured that the investigational products were manufactured in accordance with GMP; the labeling also complied with the regulatory requirement.

\section{Drugs}

The reference product was Glivec tablets $400 \mathrm{mg}$ (containing $400 \mathrm{mg}$ Imatinib as Imatinib mesylate) manufactured by Novartis Pharma AG, Basle, Switzerland, batch number: S0143 (manufacture date:2009 and expiry date: $02 / 2011$ ). The test product was Imatinib tablets $400 \mathrm{mg}$ as Imatinib mesylate developed by Hikma Pharmaceuticals PLC, batch number: 2090602, manufactured 06/2009.

\section{Subjects}

Twenty-two (22) subjects were included in the study. The physician's Desk Reference rates Imatinib in the pregnancy category D. Therefore, for the safety of the subjects, it was unacceptable to include women in the present study, therefore, all volunteers were male. Also, all volunteers were non- or ex-smokers, of at least 18 years of age, but not older than 55 years with a body mass index (BMI) greater than or equal to 18.5 and below $30 \mathrm{~kg} / \mathrm{m} 2$. All subjects were selected according to the inclusion and exclusion criteria. They were healthy according to medical history, physical examination (including vital signs) and laboratory tests (hematology, biochemistry, and urinalysis). Also, all volunteers were negative regarding HIV, Hepatitis B and Hepatitis C tests as well as negative screening of ethyl alcohol and drugs of abuse in urine.

Many studies, reported in literature, were conducted by Novartis (Originator of Glivec) on healthy subjects, in order to evaluate metabolism and disposition of Imatinib [9], bio-equivalency of Imatinib between different dosage forms (such as tablets and capsules) $[10,11]$ and interactions between Imatinib and other drugs (such as ketoconazole and rifampicin) $[14,15]$. There is also a study conducted on healthy male South American volunteers in Uruguay to assess the bioequivalence of a test formulation and Glivec [16]. Therefore, healthy subjects were included in this study.

\section{Study design and blood sampling}

This study was single center, randomized, single dose, laboratory blinded, 2-period, 2-sequence, crossover design. Subjects were assigned a number upon check-in of period 1. Each subject retained this number throughout the study. The order of investigational product administration was sequentially assigned from a computergenerated randomization list using clinical, an application developed at Algorithme Pharma, provided to the personnel who dispensed the study drugs. In each study period, a single $400 \mathrm{mg}$ dose of Imatinib tablets was orally administered with about $240 \mathrm{~mL}$ of water. The volunteers were asked to fast overnight for $10 \mathrm{~h}$ and took the dose in the next morning after $30 \mathrm{~min}$ of the start of a high-fat, high calorie breakfast. Subjects remained seated for at least the first 4 hours following each drug administration. In each study period, twenty blood samples 
were collected by venipuncture in pre-cooled Vacutainers containing EDTA. The first blood sample $(2 \times 4 \mathrm{~mL})$ was collected prior to drug administration while the others ( $1 \times 4 \mathrm{~mL}$ each) were collected at 1 , $1.5,2,2.33,2.67,3,3.33,3.67,4,4.5,5,6,8,10,14,18,24,48$ and 72 $\mathrm{h}$ post drug administration. The drug administrations were separated by at least 14 calendar days. Urine drug and ethyl alcohol screening was performed before each period of the study. Hematology and biochemistry tests were repeated after the collection of the last blood sample of the study. Safety was evaluated through the assessment of adverse events, and laboratory tests. All adverse events that occurred during the study were documented. Subjects were questioned about any symptoms or unexpected occurrences during the study. All adverse events, regardless of severity or relationship to the study drug, were recorded in the case report forms.

\section{Drug assay}

Imatinib plasma samples were analyzed employing a validated HPLC method using MS/MS detection. The analytical method procedures comply with the following regulatory guidelines: FDA guidance for industry: Bioanalytical method validation (May 2001); FDA good laboratory practice for non-clinical laboratory studies: Title 21 CFR part 58.

Ten calibrants and 4 levels of quality control samples were prepared with drug free human plasma. All calibrant and QC samples were stored at a temperature of $-20^{\circ} \mathrm{C}$ nominal for use during study sample analysis. Calibrant concentrations of Imatinib ranged from $10.0 \mathrm{ng} / \mathrm{mL}$ to $4000.0 \mathrm{ng} / \mathrm{mL}$. QC sample concentrations of Imatinib were prepared at different levels in order to have QC concentration levels that reflect the majority of study sample concentrations. The calibration curves were linear with a correlation coefficient (r2) of 0.999. The lower limit of quantitation (LLOQ) of this method was found to be $10.0 \mathrm{ng} / \mathrm{mL}$ for Imatinib. Sample pretreatment involved liquid-liquid extraction of Imatinib from human plasma. Percent extraction yield of Imatinib in human plasma were around $95 \%+1 \%$.

\section{Pharmacokinetic parameters and statistical analysis}

A noncompartmental model was used to determine the pharmacokinetic parameters of Imatinib. The main pharmacokinetic parameters of interest for this study were $C_{\max }, A C_{0-\mathrm{T}}$ and $\mathrm{AUC}_{0-\infty}$. Other parameters such as $\mathrm{T}_{\max }, \mathrm{AUC}_{\mathrm{T} / \infty}, \mathrm{K}_{\mathrm{el}}$ and $\mathrm{T}_{1 / 2 \mathrm{el}}$ were provided for information purposes only. The natural logarithmic transformation of $\mathrm{C}_{\max }, \mathrm{AUC}_{0-\mathrm{T}}$ and $\mathrm{AUC}_{0-\infty}$ was used for all statistical inference. Statistical analysis of $\mathrm{T}_{\max }$ based on a non-parametric approach. Statistical analysis of all other pharmacokinetic parameters based on a parametric random ANOVA model. Two-sided 90\% confidence interval of the ratio of geometric LS means obtained from the lntransformed pharmacokinetic parameters.

Statistical and pharmacokinetic analysis were generated using Kinetic, an application developed at Algorithme Pharma and SAS (Version 9.1 or higher) using the mixed procedure.

\section{Results}

The bioequivalence study was conducted in 22 healthy male volunteers. One of the volunteers was withdrawn from the study in period one due to vomiting. Demographic characteristics (mean [SD]) for the overall group included in the study was as follow: age, 39 (11) years; weight, 78.7 (9.4) kg; height, $175.4(7.4) \mathrm{cm}$; and BMI, 25.6 (3.0) $\mathrm{kg} / \mathrm{m}^{2}$.
Under fed conditions, the $\mathrm{C}_{\max }, \mathrm{T}_{\max }, \mathrm{AUC}_{0-\mathrm{T}}$ and $\mathrm{AUC}_{0-\infty}$ for Imatinib tablets $400 \mathrm{mg}$ and Glivec were similar in healthy male adult volunteers. The LSM ratios were very narrow with low ISCV (12.9\%) for $\mathrm{C}_{\max }$ and (5\%) for both $\mathrm{AUC}_{0-\mathrm{T}}$ and $\mathrm{AUC}_{0-\infty}$ (Table 1 and 2). The mean plasma concentration versus time (pharmacokinetic) profiles were superimposed on each other (Figure 2). The mean parameters tested $\mathrm{C}_{\max }, \mathrm{T}_{\max }, \mathrm{AUC}_{0-\mathrm{T}}$ and $\mathrm{AUC}_{0-\infty}$ were very similar for both -formulations.

21 out of 22 male subjects received the medication and 21 completed the study. One of the Subjects was withdrawn from the study in period one due to vomiting. There was no significant deviation or adverse event that could affect the pharmacokinetic profile.

Nine (9) of the twenty-two subjects included in the study experienced a total of fourteen (14) adverse events during the study. Five (5) adverse events ( 5 different types) were reported after the single dose administration of the test product and ten (10) adverse events (8 different types) were reported after the single dose administration of the reference product. One (1) adverse event (blood bilirubin increased) associated with post study laboratory test results were imputed to both formulations. Three (3) adverse events judged to be possibly related to the investigational products (polydipsia, feeling hot and urine abnormality) were unexpected. No serious adverse events were recorded in this study.

\section{Discussion}

Two drug products (of the same active ingredient) are therapeutically equivalent when the rate and extent of biologic absorption of the active ingredients is essentially similar [5] Area under the curve (AUC) is accepted as a good indicator of extent of absorption, whereas $\mathrm{C}_{\max }$ and $\mathrm{T}_{\max }$ are considered estimators of the rate of absorption. Two internationally recognized organizations (U.S.Food and Drug Administration and European Agency for the Evaluation of Medicinal Products) have proposed that bioequivalence can only be assumed when the characteristic parameters of bioavailability show no more than a defined difference, which depends on the nature of the drug, the subject population, and the clinical end point.

The ratios of LSM and $90 \%$ confidence intervals for the pharmacokinetic parameters $\left(\mathrm{C}_{\max }, \mathrm{AUC}_{0-\mathrm{T}}\right.$ and $\left.\mathrm{AUC}_{0-\infty}\right)$ of Imatinib tablets $400 \mathrm{mg}$ versus Glivec tablets $400 \mathrm{mg}$ under fed conditions were

\begin{tabular}{|c|c|c|c|c|}
\hline \multirow{2}{*}{ PARAMETER } & \multicolumn{2}{|l|}{ TEST } & \multicolumn{2}{|c|}{ REFERENCE } \\
\hline & MEAN & C.V. & MEAN & C.V. \\
\hline $\mathrm{C}_{\max }(\mathrm{ng} / \mathrm{mL})$ & 1760.5 & 26.6 & 1779.4 & 25.8 \\
\hline $\mathrm{T}_{\max }$ (hours) & 3.67 & 26.4 & 3.67 & 39.0 \\
\hline $\mathrm{AUC}_{0-\mathrm{T}}(\mathrm{ng} \cdot \mathrm{h} / \mathrm{mL})$ & 30946.5 & 28.0 & 31073.6 & 25.7 \\
\hline$A \cup C_{0-\infty}(\mathrm{ng} \cdot \mathrm{h} / \mathrm{mL})$ & 31912.5 & 28.2 & 32270.9 & 26.4 \\
\hline $\mathrm{AUC}_{\mathrm{T} / \infty}(\%)$ & 97.05 & 1.6 & 96.49 & 2.3 \\
\hline $\mathrm{K}_{\mathrm{el}}\left(\right.$ hours $\left.^{-1}\right)$ & 0.0507 & 18.4 & 0.0503 & 17.3 \\
\hline $\mathrm{T}_{1 / 2 \mathrm{el}}$ (hours) & 14.07 & 16.6 & 14.18 & 17.1 \\
\hline
\end{tabular}

Table1: The Pharmacokinetic Parameters of Imatinib tablets $400 \mathrm{mg}$ versus Glivec

\begin{tabular}{|c|c|c|c|c|c|c|}
\hline \multirow[t]{2}{*}{ Parameter } & \multirow{2}{*}{$\begin{array}{l}\text { Intra-Subject } \\
\text { C.V. }(\%)\end{array}$} & \multicolumn{2}{|c|}{$\begin{array}{l}\text { Geometric } \\
\text { LSMEANS }\end{array}$} & \multirow{2}{*}{$\begin{array}{l}\text { Ratio } \\
(\%)\end{array}$} & \multicolumn{2}{|c|}{$\begin{array}{l}90 \% \text { Confidence } \\
\text { Limits }\end{array}$} \\
\hline & & Test & Reference & & Lower & Upper \\
\hline $\mathrm{C}_{\max }(\mathrm{ng} / \mathrm{mL})$ & 12.9 & 1704.4 & 1730.1 & 98.53 & 92.00 & 105.52 \\
\hline$A \cup C_{0-T}(\mathrm{ng} \cdot \mathrm{h} / \mathrm{mL})$ & 6.3 & 29718.5 & 30036.7 & 98.94 & 95.69 & 102.31 \\
\hline$A \cup C_{0-\infty}(\mathrm{ng} \cdot \mathrm{h} / \mathrm{mL})$ & 6.0 & 30623.6 & 31142.0 & 98.34 & 95.23 & 101.55 \\
\hline
\end{tabular}

Table 2: Comparison of results with standards for Bioequivalence. 
Citation: Jawhari D, AISwisi M, Ghannam M (2011) Bioavailability of a New Generic Formulation of Imatinib Mesylate 400mg Tablets Versus Glivec in Healthy Male Adult Volunteers. J Bioequiv Availab 3: 161-164. doi:10.4172/jbb.1000077

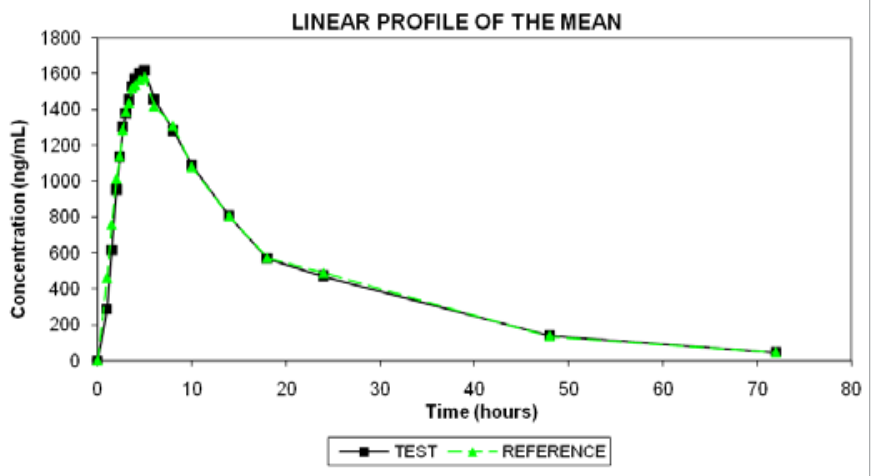

Figure 2: Plasma concentrations of Imatinib tablets 400mg (Test) and glivec (Reference).

within $80 \%$ to $125 \%$ FDA acceptance range for generic drugs which indicated that Imatinib tablets $400 \mathrm{mg}$ and Glivec tablets $400 \mathrm{mg}$ are bioequivalent under fed conditions. The pharmacokinetics of the formulations tested was the same and healthy subjects were well tolerated to Imatinib and no major side effects were observed.

\section{Conclusion}

Based on statistical results, it can be concluded that both products tested in this study comply with regulatory requirements to be claimed bioequivalent. According to the above, the test product can be considered interchangeable with the reference based on their biopharmaceutical performance. Both products were well tolerated of Imatinib included in this study are bioequivalent, and that both products can be considered equally effective and interchangeable in medical practice based on the pharmacokinetic effect.

\section{Acknowledgment}

All authors are employees of Hikma Pharmaceuticals Plc, which is the sponsor of the Bioequivalence study for Imatinib $400 \mathrm{mg}$ tablets. The authors wish to acknowledge the support of Hikma pharmaceuticals Research and development Department-Oncology section. The authors thank Dr.Francisco Carrizo-Technical Director for "Center for Clinical Pharmacology, Bdbeq S.A" Hospital Italiano Umberto Primo, Primer piso.Bulevar Artigas 1632, 11600 Montevideo, URUGUAY for critical review. Many thanks to Dr. Ayman Abbas for his review.

\section{References}

1. Robinson DR, Wu YM, Lin SF (2000) The protein tyrosine kinase family of the human genome. Oncogene 19: 5548-57.

2. Savage DG, Antman KH (2002) Imatinib Mesylate - A New Oral Targeted Therapy. N Engl J Med 346: 683-93.

3. Peng B, Lloyd P, Schran H (2005) Clinical pharmacokinetics of Imatinib. Clinical Pharmacokinetics 44: 879-94.

4. Faderl S, Talpaz M, Estrov Z, O’Brien S, Kurzrock R, Kantarjian HM (1999) The Biology of Chronic Myeloid Leukemia.The New England Journal Of Medicine 341: 164-172.

5. Peng B, Hayes M, Resta D, Racine-Poon A, Druker BJ, et al. (2004) Pharmacokinetics and pharmacodynamics of Imatinib in a phase I trial with chronic myeloid leukemia patients. J Clin Oncol 22: 935-42.

6. Kubota T (2006) Gastrointestinal stromal tumor (GIST) and imatinib. Int J Clin Oncol 11: 184-189.

7. Petain A, Kattygnarath D, Azard J, Chatelut E, Delbaldo C, et al. (2008) Innovative Therapies with Children with Cancer European consortium. Population pharmacokinetics and pharmacogenetics of Imatinib in children and adults. Clin Cancer Res 14: 7102-9.

8. Druker BJ, Talpaz M, Resta DJ, Peng B, Buchdunger E, (2001) Safety of a Specific Inhibitor of the BCR-ABL Tyrosine Kinase in Chronic Myeloid Leukemia. N Engl J Med 344: 1031-7.
9. Gschwind HP, Pfaar U, Waldmeier F, Zollinger M, Sayer C, et al. (2005) Metabolism and disposition of Imatinib mesylate in healthy volunteers. Drug Metab Dispos 33: 1503-12.

10. Peng B, Dutreix C, Mehring G, Hayes MJ, Ben-Am M, et al. (2004) Absolute bioavailability of Imatinib (Glivec) orally versus intravenous infusion. J Clin Pharmacol 44: 158-62.

11. Nikolova Z, Peng B, Hubert M, Sieberling M, Keller U, et al. (2004) Bioequivalence, safety, and tolerability of Imatinib tablets compared with capsules. Cancer Chemother Pharmacol 53: 433-8.

12. van Erp NP, Gelderblom H, Guchelaar HJ (2009) Clinical pharmacokinetics of tyrosine kinase inhibitors. Cancer Treat Rev 35: 692-706.

13. van Erp NP, Gelderblom H, Karlsson MO, Li J, Zhao M, et al. (2007) Influence of CYP3A4 inhibition on the steady-state pharmacokinetics of Imatinib. Clin Cancer Res 13: 7394-400.

14. Dutreix C, Peng B, Mehring G, Hayes M, Capdeville R, et al. (2004) Pharmacokinetic interaction between ketoconazole and Imatinib mesylate (Glivec) in healthy subjects. Cancer Chemother Pharmacol 54: 290-4.

15. Bolton AE, Peng B, Hubert M, Krebs-Brown A, Capdeville R, et al. (2003) Effect of rifampicin on the pharmacokinetics of Imatinib mesylate (Gleevec, STI571) in healthy subjects. Cancer Chemother Pharmacol 53: 102-6.

16. Parrillo-Campiglia S, Ercoli MC, Umpierrez $\mathrm{O}$, Rodríguez $\mathrm{P}$, Márquez $\mathrm{S}$, et al. (2009) Bioequivalence of two film-coated tablets of imatinib mesylate 400 $\mathrm{mg}$ : a randomized, open-label, single-dose, fasting, two-period, two-sequence crossover comparison in healthy male South American volunteers. Clin Ther 31: 2224-32. 